\title{
PSYCHIATRIC MANIFESTATIONS IN MULTIPLE SCLEROSIS PATIENTS AND MULTIPLE SCLEROSIS IN PSYCHIATRIC PATIENT
}

A recent paper from Fazzito et al.' brought attention to psychiatric disorders found in association with multiple sclerosis (MS) and concluded that, although infrequent, several psychiatric conditions may be present during the course of MS. We have recently diagnosed MS in a patient suffering from schizo- phrenia and the difficulties in such a diagnosis are indeed overwhelming.

This case report was approved by the Ethics Committee of Universidade Metropolitana de Santos, SP, and the patient's adoptive mother gave her consent for its publication.
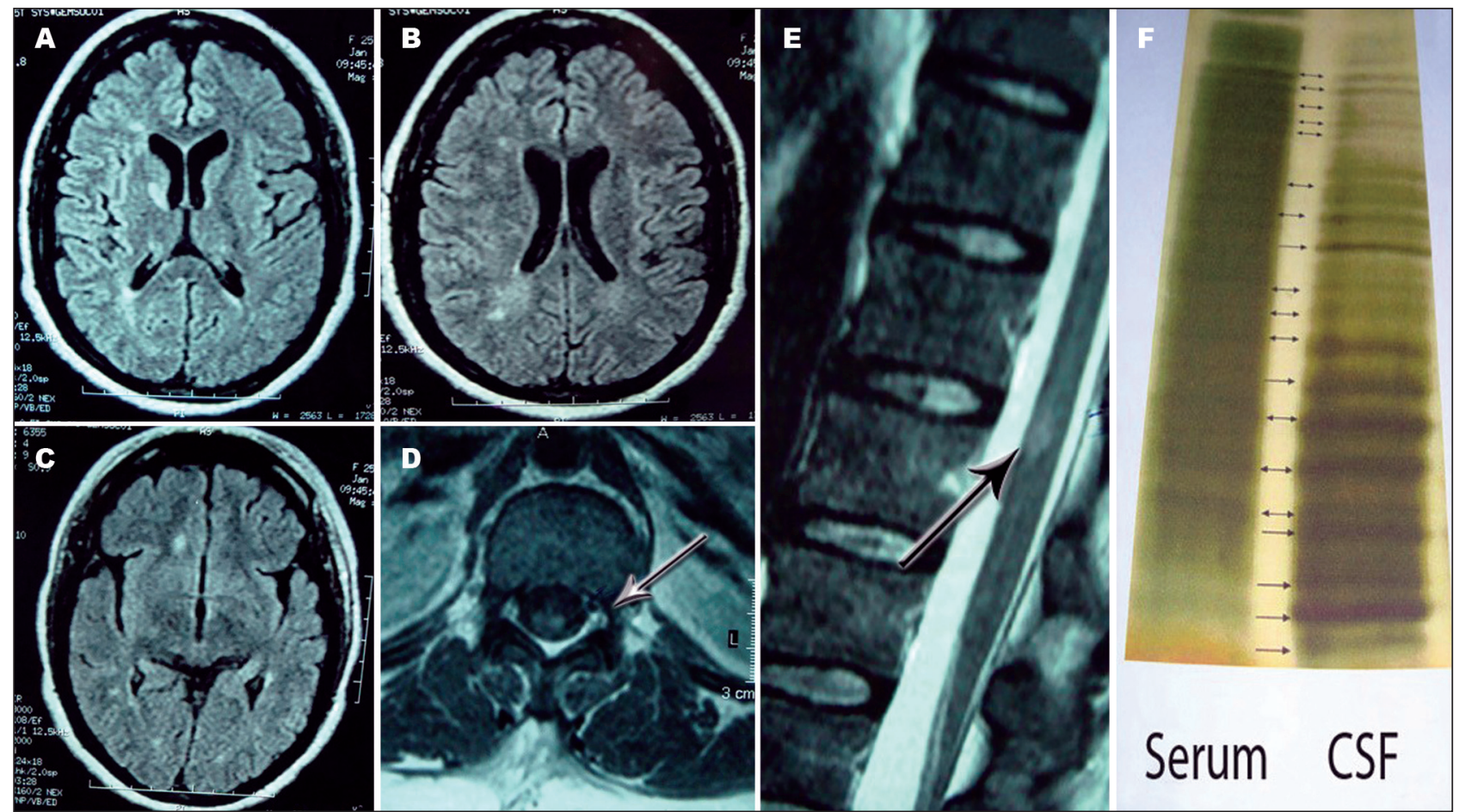

Figure. $[A, B, C] \rightarrow$ Brain MRI images (T2-FLAIR); $[D, E] \rightarrow$ T11 spinal MRI images; $[F] \rightarrow[B]$. 
A 29-year-old female who had been adopted as a young child, with no data on her family history, had had an unremarkable childhood except for slow progression at school. At the age of 15 , she had her first suicide attempt, induced by voices that told her to kill herself. Her speech became incoherent with increasing frequency; her affective relationships were exclusively towards her adoptive parents; while a state of progressive avolition and disorganization became clear. She subsequently attempted suicide more than ten times, always induced by voices that urged her to finish her life.

At the age of 25 , she complained of sensory symptoms in her lower limbs. Her adoptive mother noticed that she was not walking as she usually did. Her medications were changed several times, since these symptoms were considered to be related to drug side effects. She refused to walk and frequently fell when forced to move around the house. Medication changes made her drowsy, worsening the gait and falls. Then, over a period of two months, all her symptoms improved. Over the next four years, five similar episodes occurred, and the psychiatrist in charge referred her to a neurologist. She underwent detailed investigation, showing normal results for blood cell counts and serum biochemistry. The results were negative for rheumatological diseases, viruses, bacteria and fungi that could manifest neurological signs and symptoms.

Her MRI images are summarized in the Figure. Her CSF was normal, except for $23.6 \%$ gamma globulin $(6.1 \mathrm{mg} / \mathrm{dL} \mathrm{IgG}$ ) and positive oligoclonal bands (Figure).

No relationship between MS relapses and psychiatric symptom worsening could be definitely established. The patient is undergoing treatment with glatiramer acetate and has had no MS relapses since, although a recent psychotic attack led to hospitalization in a highly regarded psychiatric hospital. During her hospitalization, she managed to get hold of blades to, once again, attempt suicide.

\section{REFERENCE}

1. Fazzito MM, Jordy SS, Tilbery CP. Psychiatric disorders in multiple sclerosis patients. Arq Neuropsiquiatr 2009;67:664-667.

\section{Yára Dadalti Fragoso ${ }^{7}$ \\ Joseph Bruno Bidin Brooks ${ }^{2}$ \\ 'Multiple Sclerosis Reference Center, DRS IV, Santos, SP. Head of the Neurology Department. Universidade Metropolitana de Santos, SP. ${ }^{2}$ Multiple Sclerosis Reference Center, DRS IV, Santos, SP. Lecturer in Neurophysiology. Universidade Metropolitana de Santos, SP.}

Dra. Yára Dadalti Fragoso - Rua da Constituição 374 - 11015-470

Santos SP - Brasil. E-mail: yara@bsnet.com.br

No conflicts of interest to declare. 